Dicle University Journal of Engineering (DUJE)

web: http://dergipark.gov.tr/dumf

Araştırma Makalesi / Research Article

\title{
Kayseri İli İçin Büyükbaş Hayvan Atığından Biyogaz ve Elektrik Üretim Potansiyelinin ve Maliyetinin Araştırılması
}

\author{
Investigation of The Biogas and Electric Production Potential and Cost from The \\ Cattle Waste in Kayseri \\ Hande NURALAN POYRAZ ${ }^{1}$, Gülşah ELDEN² ${ }^{2}$ Gamze GENÇ* \\ ${ }^{1}$ Erciyes Üniversitesi, Fen Bilimleri Enstitüsü, Enerji Sistemleri Mühendisliği ABD, Kayseri, hnuralan@hotmail.com \\ ${ }^{2}$ Erciyes Üniversitesi, Mühendislik Fakültesi, Enerji Sistemleri Mühendisliği Bölümü, Kayseri, gulsah@erciyes.edu.tr \\ ${ }^{3}$ Erciyes Üniversitesi, Mühendislik Fakültesi, Enerji Sistemleri Mühendisliği Bölümü, Kayseri, gamzegenc@erciyes.edu.tr
}

\begin{tabular}{l} 
MAKALE BİLGİLEİ \\
\hline Makale geçmişi: \\
Geliş: 31 Mayıs 2020 \\
Düzeltme: 28 Haziran 2020 \\
Kabul: 7 Temmuz 2020 \\
\hline Anahtar kelimeler: \\
Biyogaz Enerjisi, Biyogaz Üretim \\
Potansiyeli, Elektrik Üretim \\
Potansiyeli, Kademelendirilmiş \\
Enerji Maliyeti
\end{tabular}

Doi: $10.24012 /$ dumf. 745837

\begin{abstract}
ÖZET
Bu çalışmada Kayseri ili Kocasinan ve Melikgazi ilçelerindeki büyükbaş hayvan atı̆̆ından biyogaz ve elektrik üretim potansiyelleri araştırılmıștır. Ayrıca, biyogaz ve elektrik üretimini ekonomik ve çevresel açıdan da değerlendirmek üzere 3 farklı durum ele alınmıştır. Birinci durumda tüm atıkların bir, ikinci durumda iki ve üçüncü durumda üç farklı tesiste toplanacağı kabul edilmiştir. Ele alınan her bir durumda atıkların taşınması ve biyogazdan elektik üretimi kaynaklı açığa çıkan $\mathrm{CO}_{2}$ salınımları ve kademelendirilmiş enerji maliyet modeli kullanılarak elektrik üretim maliyeti belirlenmiștir. Elde edilen sonuçlara göre en yüksek biyogaz ve elektrik üretim potansiyeli Kocasinan ilçesinde bulunan Oymağaç mahallesindedir. Bununla beraber, çevresel açıdan en düşük $\mathrm{CO}_{2}$ salınımı DURUM III'de gerçekleşirken, ekonomik açıdan ise en düşük elektrik üretim maliyeti DURUM II'de elde edilmiştir.
\end{abstract}

\begin{tabular}{|c|c|}
\hline ARTICLE INFO & ABSTRACT \\
\hline Article history: & \multirow{6}{*}{$\begin{array}{l}\text { In this study, the potentials of biogas and electric production from the cattle waste in the Kocasinan and Melikgazi } \\
\text { districts of Kayseri were investigated. Furthermore, three different cases were considered in order to evaluate the } \\
\text { productions in terms of environmental and economic aspects. It is assumed that the waste can be collected in the } \\
\text { one, two and three plants in the first, second and third cases, respectively. In all considered cases, } \mathrm{CO}_{2} \text { emission } \\
\text { resulted from transporting of waste and electric production from biogas was determined and electric production } \\
\text { cost was calculated by using levelized cost of electricity method. The results were brought that the highest biogas } \\
\text { and electric production potential was obtained in Oymaaghaç neighborhood in Kocasinan district. However, while } \\
\text { the lowest environmental } \mathrm{CO}_{2} \text { emission was occurred in Case III, the lowest electricity production cost was } \\
\text { achieved in Case II. }\end{array}$} \\
\hline Received: 31 May 2020 & \\
\hline Revised: 28 June 2020 & \\
\hline Accepted: 7 July 2020 & \\
\hline Keywords: & \\
\hline $\begin{array}{l}\text { Biogas energy, Biogas } \\
\text { production potential, Electric }\end{array}$ & \\
\hline
\end{tabular}

\footnotetext{
* Sorumlu yazar / Correspondence

Gamze GENÇ
}

$\triangle$ gamzegenc@erciyes.edu.tr 


\section{Giriş}

Günümüzde nüfus ve sanayileşmenin artmasıyla birlikte artan enerji ihtiyacını karşılamakta en çok kullanılan fosil kökenli yakıtların rezervlerinin tükeniyor olması ve sera gazı etkilerinin getirdiği olumsuzluklar nedeniyle alternatif ve temiz enerji kaynakları ön plana çıkmaktadır. Alternatif enerji kaynakları arasında ise son yıllarda biyogaz enerjisi göze çarpmaktadır. Biyogaz enerjisi mikro algler, gida ve tarımsal atıklar, hayvan gübreleri, kümes hayvan atıkları, belediye katı atıkları, endüstriyel atıklar, orman atıkları ve çeşitli enerji bitkilerinden üretilebilir. $\mathrm{Bu}$ organik atıklar, anaerobik ortamda mikrobiyolojik floranın etkisi ile içeriğinde $\% 52$ metan gazı, \%45 $\mathrm{CO}_{2}$ ve $\% 3$ 'lük $\mathrm{H}_{2} \mathrm{~S}, \mathrm{O}_{2}, \mathrm{~N}_{2}, \mathrm{H}_{2}$ ve $\mathrm{CO}$ bulunan biyogaza dönüşür. Biyogazın içeriğindeki $\mathrm{CH}_{4}$ hariç $\mathrm{CO}_{2}$ ve diğer bileşenler uzaklaştırılarak, metan saflaştırılıp 1sı ve elektrik üretimi gerçekleştirilmektedir [1]. Çevre ve yer altı sularının kirlenmesini engellemek için hayvancılık faaliyetleri sonucunda açığa çıkan gübrelere kontrollü atık tekniği uygulamak hem çevresel etkiler hem de enerji üretimi açısından önem arz etmektedir. Dünyada ve ülkemizde günlük atık miktarının fazla olması nedeniyle, biyogaz enerjisi üretimi için, en fazla büyük baş hayvan gübresi tercih edilmektedir $[2,3]$. Ülkemiz açısından biyokütle ve biyogaz enerjisi üretiminin son zamanlarda artmasıly kamuda ve özel sektörde bu alana ilişkin yatırım faaliyetleri de büyük bir hızla artmaktadır. Ancak biyogaz enerjisi açısından ülkemizin büyük bir potansiyele sahip olmasına rağmen istenilen seviyelerde bir kaynak kullanımı ve üretiminin olmadığı görülmektedir.

Gerek hayvansal atıklar gerek bitkisel atıklardan biyogaz ve biyogazdan elektrik üretimi üzerine uzun yıllardır birçok çalışma yapılmaktadır. Achinas ve arkadaşları [4] anaerobik dönüşüm esnasında inek gübresinin koyun gübresi ile farklı oranlarda karışımları için biyogaz üretim potansiyeli araştırılmıştır ve çalışmanın sonuçlarına göre tek başına inek gübresinin biyogaz üretimi için baskın faktör oluşturduğu ve en yüksek biyogaz üretimine sahip olduğu bulunmuştur. Özer çalışmasında [5] Ardahan ili için hayvansal gübre ve tarımsal atıkları kullanarak biyogaz potansiyelini incelemiştir ve $1.72 \mathrm{Mton} / \mathrm{y} 1 \mathrm{l}$ hayvansal atık ve $48 \mathrm{bin}$ ton/y1l tarımsal atık bu atıklardan toplamda, $81 \mathrm{~m}^{3} / \mathrm{y} 11$ metan üretimi ve $323 \mathrm{GWh} / \mathrm{y} 1 \mathrm{l}$ enerji eşdeğeri bulmuştur. Belediye atıklarından temiz enerji elde edilebilmesi üzerine yapılan araştırmanın sonucunda $25.4 \mathrm{~kW} / \mathrm{yll}$ elektrik üretimi yapılabileceği ve $25 \mathrm{Mton} / \mathrm{y} 1 \mathrm{l} \mathrm{CO}_{2}$ emisyon eşdeğerinin açığa çıkacağı gösterilmiştir [6]. Meyer ve arkadaşları [7] Amerika Birleşik Devletleri'nde bulunan 28 adet eyaletin 2030 yılındaki hayvansal ve bitkisel atıklardan elde edilecek enerji potansiyelini araştırmışlardır. Fazal ve ark. [8] biyo-elektrokimyasal sistemler kullanarak farklı atık sulardan anaerobik koşullar altında mikroorganizmalardan da biyogaz üretimi yapılabileceği ifade etmiştir. Biyofilik sicaklıkta $\left(35^{\circ} \mathrm{C}\right)$ hayvan gübresi ve buğday samanı ile biyogaz elde edilebilmektedir [9]. Biyogaz üretimi için atıkların potansiyeli ve veriminin araştırılmasının yanı sıra yaşam döngü analizine dayalı biyogaz üretiminin çevresel değerlendirilmesinin de önem arz etmesinden dolayı Aziz ve arkadaşları [10] bununla ilgili olarak 2006 yılından 2013 yılına kadar yapılmış yaşam döngü analizi üzerine 48 çalışmayı gözden geçirmişlerdir. Kanarya adalarında farklı hayvan türlerinden açı̆̆a çıkan atıkların değerlendirilmesi sonucunda teorik olarak 44.7 $\mathrm{m}^{3} / \mathrm{y}$ 1l biyogaz üretimi gerçekleşirken gerçekte $27.1 \mathrm{~m}^{3} / \mathrm{y} 1 \mathrm{l}$ gerçekleşmiştir [11]. Bu üretimin yanı sira 55745.1 ton $\mathrm{CO}_{2}$ yıllik sera gazı emisyonu tasarrufu sağlanmıştır. Biyogaz üretiminde biyogaz üretimini artırmak için farklı atıklar birbiriyle karıştırılmaktadır. Wei ve arkadaşları [12] Tibet platosunda $15^{\circ} \mathrm{C}$ sicaklıkta arpa ile Tibet domuzu ve inek gübrelerinin biyogaz üretim potansiyelleri araştırdılar ve sonuç olarak arpa-Tibet domuzu ve arpa-inek gübresi karışımlarından sırası ile $233.4 \mathrm{ml} / \mathrm{Gvs}$ ve $192.0 \mathrm{ml} / \mathrm{Gvs}$ biyogaz üretilmiştir. Scarlat ve arkadaşları [13] Avrupa için çiftlik ve kümes hayvanlarının atık miktarlarına bağlı teorik olarak 26 milyar $\mathrm{m}^{3}$ biyometan üretilebileceğini belirtmişlerdir. Türker ve Avcıoğlu [14] 2009 yılında yapılan sayıma göre Türkiye'nin biyogaz potansiyelini $2.18 \mathrm{gm}^{3}$ olarak bulurken Öztürk ve arkadaşlarının [15] yaptığı çalışmaya göre 2030 y1lına kadar Türkiye'nin toplam biyogaz üretiminin 52.5 TEP değerine erişeceği belirtilmiştir. Türkiye'nin biyogaz esaslı enerji kaynaklarının potansiyel değerlendirmesine göre Türkiye'nin belediye atıklarından $4.85 \mathrm{TWh} / \mathrm{y} 1$, tarımsal atıktan $165.29 \mathrm{TWh} / \mathrm{y} 1 \mathrm{l}$ ve hayvansal atıktan $16.19 \mathrm{TWh} / \mathrm{y} 1$ biyogaz enerji üretebilme potansiyeli vardır [16]. İtalya'da farklı güçlere 
$(100 \mathrm{~kW}, 200 \mathrm{~kW}$ ve $300 \mathrm{~kW}$ 'l1k) sahip süt ineği atı̆g kullanan biyogaz tesisleri için yapılan ekonomik değerlendirmeye göre $200 \mathrm{~kW}$ gücünde tesis minimum boyutlardadır ve 350 $\mathrm{m}^{3} / \mathrm{s}$ biyometan üretilmiştir [17]. Klavon ve arkadaşları [18] yaptıkları çalışmada öncelikle ABD'de 150-200 süt ineği bulunan bir işletme için ekonomik fizibilite araştırması yapmışlardır ve ayrıca ekonomik fizibilitesi olan bir tesis için süt ineği sayısını belirlemişlerdir. Isıtma ve elektrik üretimi için biyogaz kullanımının ücreti yıllık inek başına 47-70\$ arasında değişirken, çalışmada biyogaz üretiminde ekonomik açıdan en uygun tesisin en az 250 ineğe sahip olmas1 gerektiği öne sürülmüştür. Cruz ve arkadaşları çalışmalarında [19] biyogaz tesislerinde anaerobik çürütücülerde sıcaklık, $\mathrm{pH}$, basınç gibi parametrelerin arduino ve düşük maliyetli elektronik ekipmanlar ile kontrol edilmesi durumunda tesisin veriminin arttığını ifade etmişlerdir. 2016 verilerine göre Adıyaman [20] ve Sivas [21] illerinde yapilan biyogaz potansiyel araştırma çalışmalarının sonuçlarına göre sırasıyla biyogaz ile yaklaşık $70.5 \mathrm{GWh}$ ve 246 GWh elektrik üretilebileceği belirtilmiştir.

$\mathrm{Bu}$ çalışmada Kayseri ili merkez ilçeleri olan Kocasinan ve Melikgazi ilçelerinde bulunan büyükbaş hayvan sayıları incelenmiş ve bu ilçelerden hayvan yoğunlukları fazla olan bölgeler tespit edilmiştir. Tespit edilen bu bölgelerin ilk olarak biyogaz ve elektrik üretim potansiyelleri incelenmiştir. Daha sonra tesis kurulum yeri olarak üç farklı durum incelenerek her bir durum için ayrı ayrı elektrik üretim maliyetleri ve $\mathrm{CO}_{2}$ emisyonları hesaplanmıştır.

\section{Kayseri İli Büyükbaş Hayvan Atıklarından Biyogaz Üretim Potansiyeli}

$\mathrm{Bu}$ çalışmanın amacı, Kayseri ilinde büyükbaş hayvan yetiştiriciliği en fazla olan mahallelerin biyogaz üretim potansiyelini ve üretilen biyogazdan elde edilen elektrik enerjisi miktarlarını belirlemektir. $\mathrm{Bu}$ amacı gerçekleştirmek için büyükbaş hayvan yetiştiriciliği en fazla olan Kocasinan ve Melikgazi ilçelerinde bulunan Akın, Buğdaylı, Cirgalan, Elagöz, Germir, Hasanarpa, Oymaağaç, Tanpınar, Yazır ve Yeşilyurt mahalleleri ele alınmıştır. $\mathrm{Bu}$ mahallelerin coğrafi konumları Şekil 1'de ve ele alınan mahallelerin birbirine göre mesafeleri Tablo 1'de gösterilmiştir. Ayrıca bu çalışmada, çevresel etkisi, kurulum ve işletme maliyeti en az olan biyogaz ve elektrik enerjisi üretim tesisini belirlemek için tesis yeri olarak üç farklı durum ele alınmıştır.

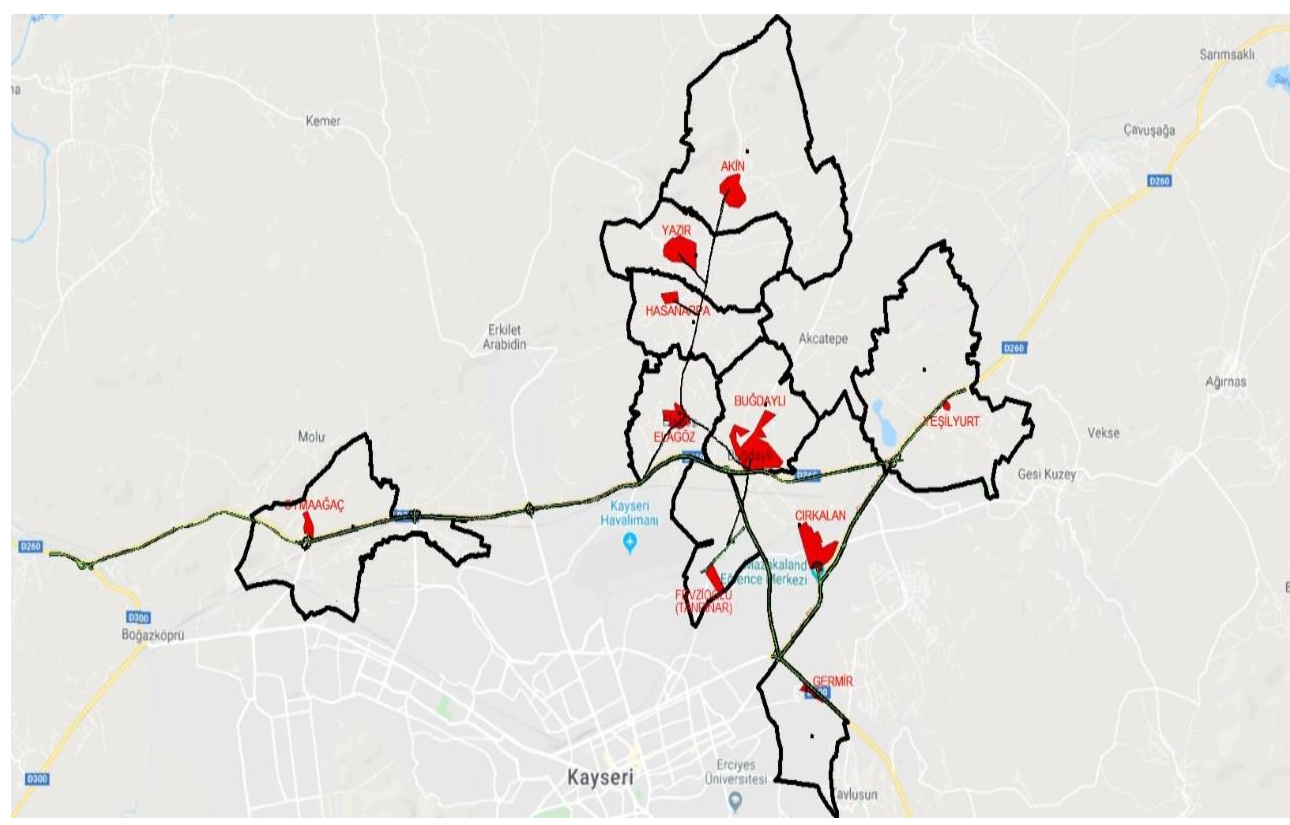

Şekil 1. Ele alınan mahallelerin coğrafi konumlar 
Tablo 1. Ele alınan mahallerin birbirine göre mesafeleri [km]

\begin{tabular}{|c|c|c|c|c|c|c|c|c|c|}
\hline Germir & 17.3 & & & & & & & & \\
\hline Cirgalan & 9.7 & 9 & & & & & & & \\
\hline Tanpınar & 14.7 & 9.1 & 6.7 & & & & & & \\
\hline Buğdaylı & 12.5 & 7.1 & 2.8 & 4.8 & & & & & \\
\hline Elagöz & 14.9 & 9.6 & 5.3 & 7.2 & 3.2 & & & & \\
\hline Hasan Arpa & 18.4 & 13 & 8.7 & 10.7 & 6.6 & 3.8 & & & \\
\hline Yazır & 19.6 & 14.3 & 10 & 11.9 & 7.9 & 5.1 & 1.6 & & \\
\hline Akın & 21.1 & 15.7 & 11.5 & 13.4 & 9.4 & 6.6 & 4.9 & 2.8 & \\
\hline Oymaağaç & 25.4 & 21.6 & 19.3 & 17.9 & 17.4 & 14.5 & 17.7 & 19.4 & 21.9 \\
\hline $\mathbf{K m}$ & Yeşilyurt & Germir & Cirgalan & Tanpınar & Buğdaylı & Elagöz & HasanArpa & Yazır & Akın \\
\hline
\end{tabular}

Kayseri ilinde bulunan Melikgazi ve Kocasinan ilçelerindeki büyükbaş hayvan yetiştiriciliği (süt sığırı) en fazla olan mahallelerdeki biyogaz üretim potansiyelini ortaya çıkarmak için aşağıdaki kabuller yapılarak mahallelere göre biyogaz ve özgül metan üretim miktarları literatürde yer alan hesaplamalar yardımıyla [22] hesaplanmıştır.

- Toplam atık miktarı (TAM) hesaplanırken büyük baş hayvan (süt sığırı) başına günlük atık miktarı $43 \mathrm{~kg}$ olarak kabul edilmiştir.

- Açığa çıkan gübrenin \%13.95'i kuru madde (KM) ve kuru maddenin ise \%83.33'ü organik kuru madde (OKM) olarak hesaba katılmıştır [22].

Oluşacak biyogaz üretim potansiyeli $\left(B \ddot{P}, \mathrm{~m}^{3}\right.$ ) ve özgül metan üretim (ÖMÜ, $\mathrm{m}^{3} \mathrm{CH} 4$ ) miktarı ise sırasıyla Eş. 1 ve Eş. 2 ile elde edilmiştir.

$\mathrm{BÜP}=\mathrm{OKM} \times 0.30$

ÖMÜ=OKMx 0.18

Biyogazdan üretilebilecek 1S1 miktar1 (BSI, GJ/y1l) ve elektrik enerjisi miktarı (BSE, $\mathrm{kWh} / \mathrm{y}$ 1l) sırasıyla Eş.3 ve Eş.4 ile hesaplanmıştır.
BSI=BÜPx0.021

$\mathrm{BSE}=\mathrm{BÜP} \times 4.7$

\section{Bulgular}

Biyogaz üretim miktarı ve bu biyogazdan üretilecek olan elektrik enerjisi miktarları ele alınan her mahalle için ayrı ayrı hesaplanmıştır. Ayrıca bu çalışmada, kurulacak olan biyogaz üretim tesisi için üç farklı durum ele alınarak bu durumların çevresel etkileri araştırılmış olup her bir durum için detaylı bir maliyet analizi de yapılmıştır.

\section{Atık Miktarlarının Değişimi}

Tablo 2'de her bir mahallede bulunan hayvan sayısı ve bu hayvanlardan açığa çıkan yıllık atık miktarı, kuru madde ve organik kuru madde miktarları verilmiştir. En fazla büyükbaş hayvan Oymaağaç'ta (8251 adet) iken en az büyükbaş hayvan Cirgalan mahallesindedir (192 adet).

Tablo2. Mahallelere göre hayvan sayıları ve atık miktarları

\begin{tabular}{|l|c|c|c|c|}
\hline Mahalleler & $\begin{array}{c}\text { Büyükbaş } \\
\text { Hayvan Adedi }\end{array}$ & $\begin{array}{c}\text { TAM } \\
\text { (Toplam Atık Miktarı) } \\
\text { [ton/yıl] }\end{array}$ & $\begin{array}{c}\text { KM } \\
\text { (Kuru Madde Miktarı) } \\
\text { [ton/yıl] }\end{array}$ & $\begin{array}{c}\text { OKM } \\
\text { (Organik Kuru Madde Miktarı) } \\
\text { [ton/yıl] }\end{array}$ \\
\hline Akın & 2052 & 32206.140 & 4492.757 & 3743.814 \\
\hline Buğdaylı & 2677 & 42015.515 & 5861.164 & 4884.108 \\
\hline Cırgalan & 192 & 3013.440 & 420.375 & 350.298 \\
\hline Elagöz & 7923 & 124351.485 & 17347.032 & 14455.282 \\
\hline Germir & 1205 & 18912.475 & 2638.290 & 3298.487 \\
\hline Hasan Arpa & 1805 & 28329.475 & 3951.962 & 15053.708 \\
\hline Oymaağaç & 8251 & 129499.445 & 18065.173 & 2391.881 \\
\hline Tanpınar & 1311 & 20576.145 & 2870.372 & 4718.081 \\
\hline Yazır & 2586 & 40587.270 & 5661.924 & 7139.154 \\
\hline Yeşilyurt & 3913 & 61414.535 & 8567.328 & 58227.985 \\
\hline Toplam & 31915 & 500905.925 & 69876.377 & \\
\hline
\end{tabular}


Yapılan hesaplamalar neticesinde en fazla hayvan potansiyeli olan Oymaağaç mahallesinde 129499.445 ton/y1l toplam atık, 18065.173 ton/y1l kuru madde, 15053.708 ton/y1l organik kuru madde olduğu en düşük hayvan potansiyeli olan Cirgalan mahallesinde ise 3013.440 ton/y1 toplam atık, 420.375 ton/y1l kuru madde, 350.298 ton/yıl organik kuru madde miktarı olduğu tespit edilmiştir.

\section{Biyogaz ve Özgül Metan Üretim Potansiyeli}

Mahaller bazında biyogaz ve özgül metan üretim potansiyelleri Şekil 2'de sunulmuştur. Şekilden görüldügü üzere en fazla biyogaz ve özgül metan üretim potansiyeli sırası ile Oymaağaç, Elagöz ve Yeşilyurt'tadır. Oymaağaç'taki biyogaz ve özgül metan üretim potansiyelleri sirasiyla $4516.112 \cdot 103 \mathrm{~m}^{3} / \mathrm{y} 11$ ve $2709.667 \cdot 103 \mathrm{~m}^{3} / \mathrm{y} 11^{\prime}{ }^{\prime} 1 \mathrm{r}$. En düşük potansiyele sahip olan Cirgalan'da ise sirası ile $105.090 \cdot 103 \mathrm{~m}^{3} / \mathrm{y} 1 \mathrm{l}$ ve $63.054 \mathrm{~m}^{3} / \mathrm{y} 1 \mathrm{l}$ 'dır.

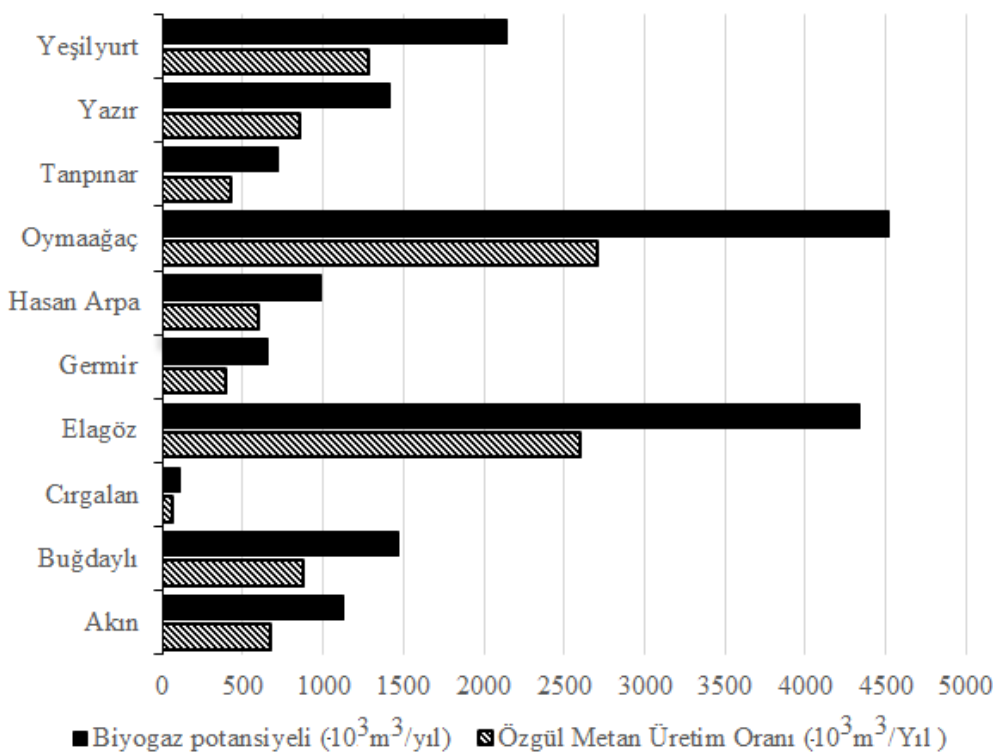

Şekil 2. Mahallelere göre biyogaz ve özgül metan üretimi potansiyeli

\section{Elektrik Üretim Potansiyeli}

Şekil 3'te verilen grafikte mahalleler bazında üretilen elektrik enerjisi miktarları verilmiştir. Biyogaz ve özgül metan üretim potansiyellerinin yüksek olmasından dolayı elektrik enerjisi potansiyeli en iyi olan ilk üç mahalle sırası ile Oymaağaç, Elagöz ve Yeşilyurt'tur. En yüksek elektrik üretimi $21.23 \mathrm{GWh} / \mathrm{y} 1 \mathrm{l}$ ile Oymaağaçta gerçekleşmektedir. Ele alınan mahallelerin tamaminda toplam $82.1 \mathrm{GWh} / \mathrm{y} 1 \mathrm{l}$ elektrik üretilmektedir.

\section{Tesis Kurulum Sahasının Belirlenmesi}

Sürdürülebilir bir biyogaz ve elektrik üretimi için ekonomik ve çevresel değerlendirme yapmakta önem arz etmektedir. Bu nedenle bu çalışmada biyogazdan elektrik üretimini ekonomik ve çevresel etkiler açısından da değerlendirmek üzere tesis kurulum yerinin belirlenmesi için farklı planlamalar yapılmıştır. Yapılan planlamalarda özellikle hayvansal atıkların taşınması ve biyogaz üretimi esnasında açığa çıkan $\mathrm{CO}_{2}$ miktarının değișimi incelenmiștir. $\mathrm{Bu}$ bağlamda 3 farklı durum ele alınmıştır. Birinci durumda (DURUM I) mevcut büyükbaş hayvan atıklarının tamamının en fazla atık potansiyeli olan Oymaağaç'ta toplanarak tesisin Oymaağaç'a kurulması planlanmıștır. İkinci durumda (DURUM II) hem potansiyelinin yüksek olması hem de konum itibari ile diğer mahallere uzak olması nedeni ile Oymaağaç'a bir tesis ve diğer mahalleler arasında daha merkezi konuma sahip olmasından dolayı bir tesiste Buğdaylı da olmak üzere iki adet tesis kurulumu planlanmıștır. DURUM II'de Oymaağaç hariç tüm mahallelerdeki atıklar Buğdaylı'ya taşınacaktır. 
Üçüncü durumda (DURUM III) ise hem atık potansiyelleri hem de konum itibari ile üç tesis kurulumu planlanmıştır. Kurulması düşünülen tesisler Oymaağaç, Yeşilyurt ve Elagöz'de yer alacaktır. DURUM III'te yine DURUM II'de olduğu gibi Oymaağaç'ta bulunan mevcut atıklar ile Oymaağaç'taki tesiste işlenirken Cirgalan, Germir ve Yeşilyurt bölgesindeki atıklar Yeşilyurt bölgesinde ve Elagöz, Yazır, Akın, Buğdaylı, Tanpınar, Hasanarpa da bulunan atıkların Elagöz'de işlenmesi planlanmıştır. Ele alınan her bir durumda atıkların taşınması ve biyogaz üretimi sonucu oluşan $\mathrm{CO}_{2}$ miktarları Tablo3'te verilmiştir. $\mathrm{Bu}$ çalışmada taşımacılıktan kaynaklanan $\mathrm{CO}_{2}$ emisyonu hesaplanırken kullanılan araçların her km'de 0.19 lt yakıt tükettiği ve kullanılan yakıtın her bir litresi başına literatüre uygun olarak $2.65 \mathrm{~kg} \mathrm{CO}_{2}$ emisyonu açığa çıktığı kabul edilmiştir [23, 24].

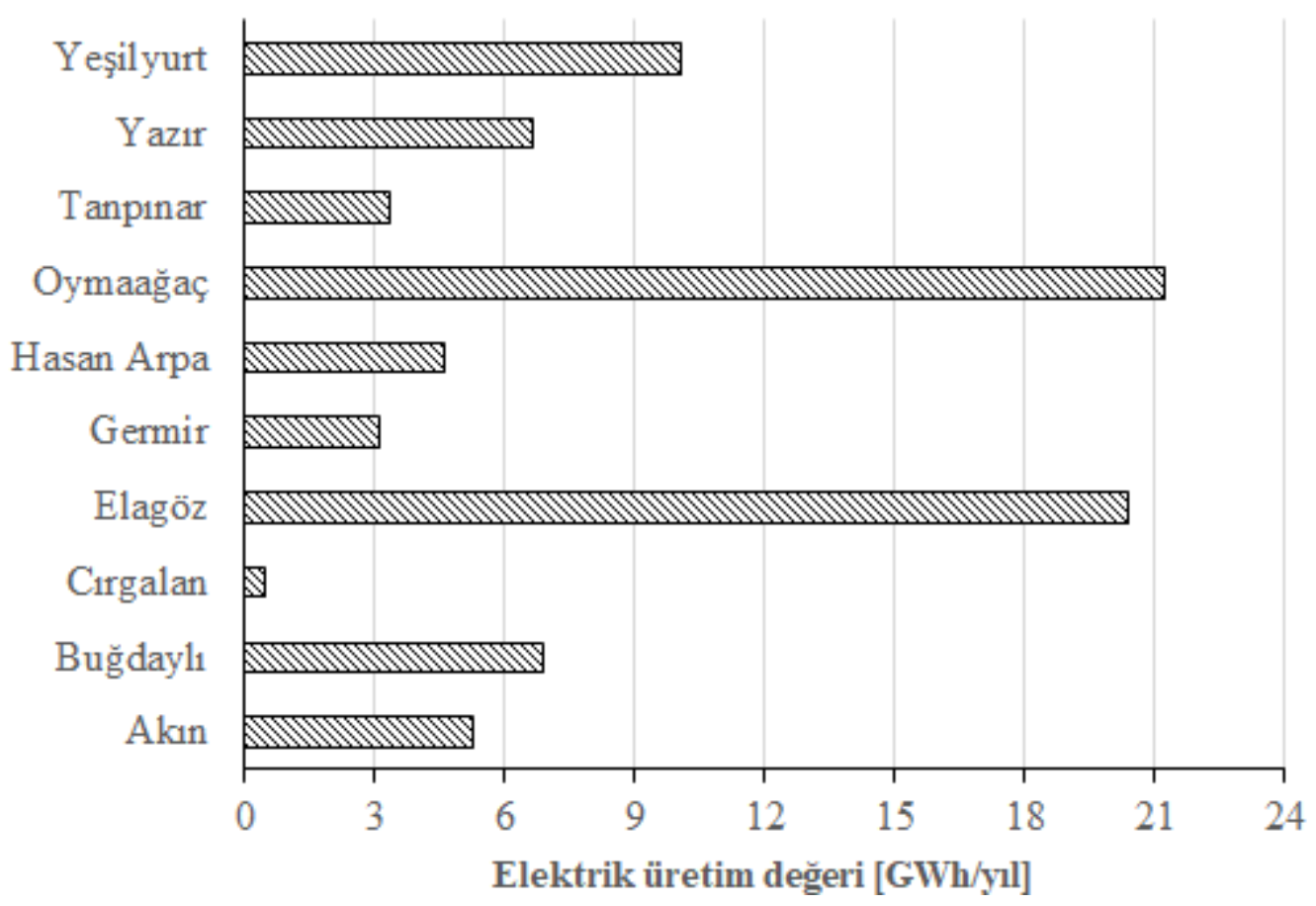

Şekil 3. Ele alınan her bir mahalle için elektrik üretim değerleri [GWh/yıl]

DURUM I'de aralarındaki mesafe en fazla olan Yeşilyurt-Oymaağaç mahalleleri arasında gübre taşıma işlemi esnasında meydana gelecek olan yıllık $\mathrm{CO}_{2}$ emisyonu 65.452 ton iken taşınacak gübre miktarının Elagöz mahallesinde çok fazla olmasindan dolayı sefer sayısı fazladır ve bundan dolayı burada taşımacılıktan kaynaklanan $\mathrm{CO}_{2}$ emisyonu 79.943 ton'dur. DURUM I'de taşımacılıktan meydana gelecek olan yıllık toplam $\mathrm{CO}_{2}$ emisyonu ise 321.895 ton olarak hesaplanmıştır. DURUM II'de atık miktarının fazla olmasına karşın Buğdaylı-Yeşilyurt mahalleleri arasindaki mesafenin fazla olmasından dolayı DURUM II içerisinde taşımacılıktan kaynaklanan yıllık $\mathrm{CO}_{2}$ emisyonu'ndaki en yüksek pay Buğdayl1Yeşilyurt arasıdır ve 32.211 ton $\mathrm{CO}_{2}$ açığa çıkmaktadır. DURUM III'te taşımacılıktan meydana gelen en fazla $\mathrm{CO}_{2}$ emisyonu ise Elagöz-Akın mahalleri arasındadır ve değeri 9.703 ton'dur. DURUM II ve DURUM III'te taşımacılıktan meydana gelen yıllık toplam $\mathrm{CO}_{2}$ emisyonu sirasiyla 97.047 ve 54.707 ton'dur.

Ele alınan her bir durumda biyogaz üretimi ve taşımacılık kaynaklı toplam $\mathrm{CO}_{2}$ emisyonunun değerleri ise Tablo 4'te verilmiştir. Kayseri ili için toplam atık potansiyeline göre elde edilen biyogazdan elektrik üretim miktarına karşılık açığa çıkacak $\mathrm{CO}_{2}$ emisyonu belirlendi. $\mathrm{Bu}$ emisyon belirlenirken literatürde yer alan birincil kaynaklı elektrik enerjisi üretiminde açığa çıkan $\mathrm{CO}_{2}$ emisyonu baz alınmıştır ve bu değer biyogaz esaslı elektrik üretimi için 26 ton- $\mathrm{CO}_{2} / \mathrm{GWh}$ 'dir [25]. 
Üretilen yıllık toplam elektrik miktarına göre bu çalışmada elektrik üretimi sonucunda açığa çıkan y1llık $\mathrm{CO}_{2}$ salınımı 2134.638 ton'dur. DURUM I, II ve III için taşımacılıktan kaynaklanan $\mathrm{CO}_{2}$ salınımları ise sirasiyla 321.895, 97.047 ve 54.707 ton'dur. Toplam $\mathrm{CO}_{2}$ salınımlarına bakıldığında incelenen üç durum içerisinde en fazla $\mathrm{CO}_{2}$ emisyonu DURUM I'de ve en düşük emisyon ise DURUM III'tedir. Taşımacılığın toplam $\mathrm{CO}_{2}$ salınımındaki payının düşük olmasına karşın taşımacılıkta üç durum kendi içinde irdelendiğinde tesisin kurulum yerinin $\mathrm{CO}_{2}$ salınımını önemli ölçüde etkilediği görülmektedir. Bu yüzden, tesis kurulum yeri bu açıdan mutlaka analiz edilmelidir. Bu çalıșmada ele alınan biyogazdan elde edilen elektrik enerjisine eşdeğer elektrik eğer doğalgaz veya ithal kömür kullanılarak gerçekleştirilseydi elektrik üretimi kaynaklı açığa çıkan $\mathrm{CO}_{2}$ emisyon miktarları sirasiyla 40968.628 ton ve 72906.095 ton olacaktır.

Tablo. 3 Ele alınan her bir durum için sefer sayılarının ve $\mathrm{CO}_{2}$ emisyonlarının değişimi

\begin{tabular}{|c|c|c|c|c|c|c|}
\hline & $\begin{array}{l}\text { Tesis } \\
\text { Yeri }\end{array}$ & Mahalleler & $\begin{array}{c}\text { Toplam Atık } \\
\text { Miktarı } \\
\text { [ton/gün] }\end{array}$ & $\begin{array}{l}\text { Günlük } \\
\text { Sefer } \\
\text { Sayısı }\end{array}$ & $\begin{array}{l}\mathrm{CO}_{2 \text {-taşıma }} \\
{[\text { ton/y1l] }}\end{array}$ & $\begin{array}{c}\mathrm{CO}_{\text {2-biyogaz-elektrik }} \\
{[\text { ton/y1l] }}\end{array}$ \\
\hline \multirow{12}{*}{ 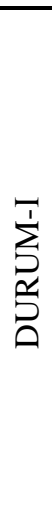 } & \multirow{11}{*}{ 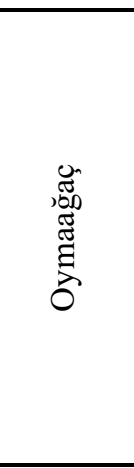 } & Ak1n & 88.24 & 8 & 32.198 & 137.248 \\
\hline & & Buğdaylı & 115.11 & 10 & 31.977 & 179.051 \\
\hline & & Cirgalan & 8.26 & 2 & 7.094 & 12.842 \\
\hline & & Elagöz & 340.69 & 28 & 79.943 & 529.931 \\
\hline & & Germir & 51.82 & 4 & 23.818 & 80.597 \\
\hline & & Hasan Arpa & 77.62 & 6 & 26.023 & 120.728 \\
\hline & & Oymaağaç & 354.79 & - & 0.000 & 551.869 \\
\hline & & Tanpınar & 56.37 & 6 & 19.738 & 87.686 \\
\hline & & Yazır & 111.20 & 10 & 35.653 & 172.965 \\
\hline & & Yeşilyurt & 168.26 & 14 & 65.452 & 261.721 \\
\hline & & Toplam & 1372.35 & & 321.895 & 2134.638 \\
\hline & & TOPLAM & 1372.35 & & 321.895 & 2134.638 \\
\hline \multirow{13}{*}{ 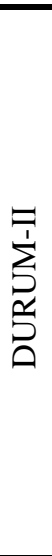 } & \multirow{10}{*}{ 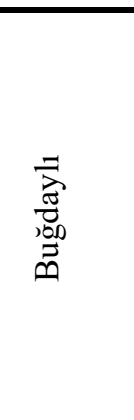 } & Ak1n & 88.24 & 8 & 13.820 & 137.248 \\
\hline & & Buğdaylı & 115.11 & - & 0.000 & 179.051 \\
\hline & & Cirgalan & 8.26 & 2 & 1.029 & 12.842 \\
\hline & & Elagöz & 340.69 & 28 & 16.696 & 529.931 \\
\hline & & Germir & 51.82 & 4 & 5.634 & 80.597 \\
\hline & & Hasan Arpa & 77.62 & 6 & 7.845 & 120.728 \\
\hline & & Tanpınar & 56.37 & 6 & 5.293 & 87.686 \\
\hline & & Yazır & 111.20 & 10 & 14.518 & 172.965 \\
\hline & & Yeșilyurt & 168.26 & 14 & 32.211 & 261.721 \\
\hline & & Toplam & 1017.55 & & 97.047 & 1582.769 \\
\hline & \multirow{3}{*}{ ఏే } & Oymaağaç & 354.79 & - & 0.000 & 551.869 \\
\hline & & Toplam & 354.79 & & 0.000 & 551.869 \\
\hline & & TOPLAM & 1372.35 & & 97.047 & 2134.638 \\
\hline \multirow{14}{*}{ 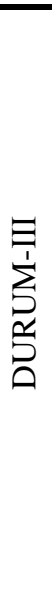 } & \multirow{4}{*}{ 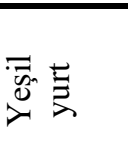 } & Cirgalan & 8.26 & 2 & 3.565 & 12.8427 \\
\hline & & Germir & 51.82 & 4 & 13.728 & 80.597 \\
\hline & & Yeșilyurt & 168.26 & - & 0.000 & 261.721 \\
\hline & & Toplam & 228.33 & & 17.293 & 355.160 \\
\hline & \multirow{2}{*}{ ఏే } & Oymaağaç & 354.79 & - & 0.000 & 551.869 \\
\hline & & Toplam & 354.79 & - & 0.000 & 551.869 \\
\hline & \multirow{8}{*}{$\begin{array}{l}N \\
: 00 \\
\frac{\mathbb{E}}{\Delta I} \\
\text { II }\end{array}$} & Elagöz & 340.69 & - & 0.000 & 529.93 \\
\hline & & Yazır & 111.20 & 10 & 9.373 & 172.96 \\
\hline & & Akın & 88.24 & 8 & 9.703 & 137.24 \\
\hline & & Buğdaylı & 115.11 & 10 & 5.881 & 179.05 \\
\hline & & Tanpınar & 56.37 & 6 & 7.939 & 87.68 \\
\hline & & Hasan Arpa & 77.62 & 6 & 4.517 & 120.72 \\
\hline & & \begin{tabular}{|l|} 
Toplam \\
\end{tabular} & 789.22 & & 37.413 & 1227.609 \\
\hline & & TOPLAM & 1372.35 & & 54.707 & 2134.638 \\
\hline
\end{tabular}


Tablo.4 Ele alınan her bir durum için sefer sayılarının ve $\mathrm{CO}_{2}$ emisyonlarının değişimi

\begin{tabular}{|c|c|c|c|}
\hline & $\begin{array}{c}\text { CO2-taşıma } \\
{[\text { ton/yıl] }}\end{array}$ & $\begin{array}{c}\mathbf{C O} \text { 2-biyogaz } \\
{[\text { ton/yıl] }}\end{array}$ & $\begin{array}{c}\text { Toplam } \mathbf{C O}_{2} \\
{[\text { ton/yıl] }}\end{array}$ \\
\hline DURUM I & 321.895 & 2134.638 & 2456.533 \\
\hline DURUM II & 97.047 & 2134.638 & 2231.685 \\
\hline DURUM III & 54.707 & 2134.638 & 2189.305 \\
\hline
\end{tabular}

\section{Maliyet Analizi}

Ele alınan her bir durum için biyogazdan elektrik üretmenin birim maliyetini bulmak için bu çalışmada kademelendirilmiş elektrik maliyet modeli kullanılmıştır. Kademelendirilmiş elektrik maliyet modelinde sistemin ilk yatırım masraflarından sistemin ömrü boyunca harcanacak olan bakım-onarım maliyetleri, işçilik maliyetleri, işletme maliyetleri gibi tüm kalemler dikkate alınarak yapılır. Ayrıca, hesaplamalarda eskalasyon oranı ve iskonto oranı gibi faktörler de dikkate alarak gerçekçi bir maliyet analizi yapılması sağlanmaktadır. Literatürdeki çalışmalar incelendiğinde bir biyogaz tesisi için $\mathrm{kW}$ güç başına özgül yatırım maliyeti $\left(M_{k W h}\right)$ ortalama $2000-5000 €$ arasinda veya $\mathrm{m}^{3}$ reaktör hacmi başına $200-500 €$ arasında değiştiği görülmektedir [22]. Biyogaz güç tesisinin ilk yatırım maliyeti Eş.5 ile hesaplanmaktadır.

$M_{B G T}=P \cdot M_{k W h}$

Burada $P$ tesisin toplam gücünü göstermektedir. Biyogaz güç tesisinin toplam yatırım maliyetinin ise yaklaşık \%40'ını biyogaz tesisi, \%30'unu kojenerasyon tesisi, \%15'ini yardımc1 ekipmanlar, \%5'ini işçilik ve kurulum maliyetleri ile \%10'unu projelendirme ve mühendislik hizmetleri oluşturmaktadır. $\mathrm{Bu}$ çalışmada özgül yatırım maliyetinin $\mathrm{kW}$ güç başına $3000 €$ olduğu kabul edilmiştir.

Sistem ömrü, iskonto oranı ve eskalasyon oranına göre hesaplanmıș bakım-onarım ve ulaşım maliyetlerini dikkate alarak birim elektrik üretimi kademelendirilmiş enerji maliyet modeline göre Eş.6 ile hesaplanabilir [26]:

$M_{e l}=\frac{M_{B T} \cdot S F_{B T}+M_{K T} \cdot S F_{K T}+M_{Y E} \cdot S F_{Y E}+M_{I K} \cdot S F_{I K}+M_{\text {proje }}+M_{B O(e s k)}+M_{\text {ulasim }(e s k)}}{E e l}$

Burada $M$ maliyetleri, $B T$ biyogaz tesisi, $K T$ kojenerasyon tesisi, $Y E$ yardımcı ekipmanları, $I K$ işçilik kurulum, proje projelendirme maliyetlerini ifade etmektedir. $B O$ (esk) ve ulaşım (esk) ise eşkâle edilmiş bakım-onarım ve ulaşım masraflarını ve $E_{e l}$ toplam elektrik üretimini göstermektedir. $S F$ sermaye dönüşüm faktörünü göstermekte olup bir ekipmanın ömrü boyunca değişen masrafını sabit hale getirmek için kullanılan yıllık değişim oranıdır ve aşağıda verilen Eş.7 ile bulunabilir.

$S F=\frac{n \cdot(1+i)^{n}}{(1+i)^{n}-1}$

Burada $i$ iskonto oranını ve $\mathrm{n}$ ise sistem ömrünü ifade etmektedir. $\mathrm{Bu}$ çalışmada iskonto oranı
$\% 10$ ve sistem ömrü $B T$ ve $K T$ için 25 y1l kabul edilmiştir.

Aşağıda verilen Eş. 6 ve 7 kullanılarak eskale edilmiş bakım-onarım ve ulaşım maliyetlerini hesaplanmıştır:

$$
\begin{aligned}
& M_{B O(e s k)}=\frac{M_{B O}}{i-e} \cdot\left(1-\frac{(1+e)^{n}}{(1+i)^{n}}\right) \\
& M_{\text {ulasim }(e s k)}=\frac{M_{\text {ulasim }}}{i-e} \cdot\left(1-\frac{(1+e)^{n}}{(1+i)^{n}}\right)
\end{aligned}
$$

$M_{B O}$ ve $M_{\text {ulasim }}$ birinci yıl için bakım-onarım ve ulaşım giderlerini göstermektedir. Bakım onarım maliyeti $\left(M_{B O}\right)$ biyogaz güç tesislerinde yaklaşık sistemin toplam maliyetinin \%6's1 kadardır. Burada $e$ eskalasyon oranını ifade etmektedir. Bakım onarım maliyeti için eskalasyon oranı 
yaklaşık \%3 iken ulaşım masrafları için \%4 kabul edilmiştir.

Çalışma kapsamında ele alınan her bir durum için sistem kurulu güç kapasiteleri, ulaşım masrafları ve hesaplanan elektrik üretim maliyetleri Tablo 5 'te verilmiştir. Tablodan görüldüğü gibi birim elektrik üretim maliyeti en düşük DURUM II'de
Buğdaylı tesisi için $(0.133 € / \mathrm{kWh})$, en yüksek maliyet ise DURUM III'de Yeşilyurt tesisi için $(0.174 € / \mathrm{kWh})$ çıkmıştır. Durumlar arasında değerlendirme yapmak için her bir durumdaki ortalama birim elektrik tüketimi dikkate alındığında ekonomik olarak en iyi durumun DURUM II olduğu ortaya çıkmıştır.

Tablo.5 Elektrik üretim maliyeti

\begin{tabular}{|c|c|c|c|c|c|c|}
\hline \multirow[b]{2}{*}{ Tesis Yeri } & \multirow{2}{*}{$\frac{\text { DURUM I }}{\text { OYMAĞAÇ }}$} & \multicolumn{2}{|c|}{ DURUM II } & \multicolumn{3}{|c|}{ DURUM III } \\
\hline & & BUĞDAYLI & OYMAĞAÇ & YEŞILIYURT & ELAGÖZ & OYMAĞAÇ \\
\hline Kurulu Güç [MW] & 14 & 10 & 4 & 3 & 8 & 4 \\
\hline $\begin{array}{l}\text { Ulaşım Masrafları } \\
\text { [€/yıl] }\end{array}$ & 125000 & 38000 & 0 & 6500 & 14500 & 0 \\
\hline $\mathbf{M}_{\mathrm{el}}[\boldsymbol{\epsilon} / \mathbf{k W h}]$ & 0.150 & 0.133 & 0.144 & 0.174 & 0.134 & 0.144 \\
\hline $\mathbf{M}_{\text {el-ort }}[€ / \mathbf{k W h}]$ & 0.150 & \multicolumn{2}{|c|}{0.139} & \multicolumn{3}{|c|}{0.151} \\
\hline
\end{tabular}

\section{Sonuçlar}

Kayseri İli merkez ilçeleri olan Kocasinan ve Melikgazi ilçelerine bağl1, en fazla büyükbaş hayvan olan Akın, Buğdaylı, Curgalan, Elagöz, Germir, Hasan Arpa, Oymaağaç, Tanpınar, Yazır, Yeşilyurt mahallelerindeki atık miktarı tespit edilerek biyogaz ve elektrik üretim potansiyellerinin ve tesis yeri olarak 3 farkl1 durumun incelendiği bu çalışmada özet olarak aşağıdaki temel sonuçlar elde edilmiştir:

- Atık miktarı en fazla olan Oymaağaç mahallesinin yıllık toplam elektrik ve biyogaz üretimindeki payı en fazladır (\%25.853).

- Ele alınan durumlar içerisinde taşımacılıktan kaynaklanan $\mathrm{CO}_{2}$ salınımları değişmektedir ve DURUM III'teki gibi tesisler kurulması durumunda en düşük salınım (54.707 ton $\mathrm{CO}_{2} /$ y1l) gerçekleşmektedir.

- Elektrik üretim maliyeti açısından inceleme yapıldığında ise en iyi durumun kWh başına $0.139 €$ ile DURUM II olduğu tespit edilmiştir.

\section{Kaynaklar}

[1] H.M. Zabed, S.Akter, J. Yun, G. Zhang, Y. Zhang, X. Qi , (2020). Biogas from microalgae: Technologies, challenges and opportunities, Renewable and
Sustainable Energy Reviews, 117, 109503.

[2] N.K. Salihoğlu, A.Teksoy, K.Altan, (2019). Büyükbaş ve Küçükbaş Hayvan Atıklarından Biyogaz Üretim Potansiyelinin Belirlenmesi Balıkesir İli Örneği, Ömer Halisdemir Üniversitesi Mühendislik Bilimleri Dergisi, 8, 31-47.

[3] H.Yağl1, Y.Koç, (2019). Hayvan Gübresinden Biyogaz Üretim Potansiyelinin Belirlenmesi: Adana İli Örnek Hesaplama, Çukurova Üniversitesi Mühendislik-Mimarlık Fakültesi Dergisi, 34, 3, 35-48.

[4] S.Achinas, Y.Li, V.Achinas, G.J.W.Euverink, (2018). Influence Of Sheep Manure Addition On Biogas Potential And Methanogenic Communities During Cow Dung Digestion Under Mesophilic Conditions, Sustainable Environment Research, 28, 5, 240-246.

[5] B.Özer, (2017). Biogas energy opportunity of Ardahan city of Turkey, Energy, 139, 1144-1152. 
[6] A.Can, (2020). The statistical modeling of potential biogas production capacity from solid waste disposal sites in Turkey, Journal of Cleaner Production, 243, 118501.

[7] A.K.P. Meyer, E.A. Ehimen, J.B. HolmNielsen, (2018). Future European biogas: Animal manure, straw and grass potentials for a sustainable European biogas production, Biomass and Bioenergy, 111, 154-164.

[8] T.Fazal, M.Sur Rehman,A. Mushtaq, A.Hafeez, F.Javed, M.Aslam, M.Fatima, A.Faisal, J. Iqbal, F.Rehman, R.Farooq, (2019). Simultaneous production of bioelectricity and biogas from chicken droppings and dairy industry wastewater employing bioelectrochemical system, Fuel, 256, 115902.

[9] L.Liu, T.Zhang, H.Wan, Y.Chen, X.Wang, G.Yang, G.Ren, (2015). Anaerobic co-digestion of animal manure and wheat straw for optimized biogas production by the addition of magnetite and zeolite, Energy Conversion and Management, 97, 132139.

[10] N.I.H.A.Aziz, M.M. Hanafiah, S.H.Gheewala, (2019). A review on life cycle assessment of biogas production:Challenges andfuture perspectives in Malaysia, Biomass and Bioenergy, 122, 361-374.

[11] J.L. Ramos-Suárez, A. Ritter, J.M. González, A. Camacho Pérez, (2019). Biogas from animal manure: A sustainable energy opportunity in the Canary Islands, Renewable and Sustainable Energy Reviews, 104, 137150.

[12] S.Wei, H.Zhang, X.Cai, J.Xu, J.Fang, H.Liu, (2014). Psychrophilic anaerobic co-digestion of highland barley straw with two animal manures at high altitude for enhancing biogas production, Energy Conversion and Management, 88, 40-48.

[13] N.Scarlat, F.Fahl, J.-F. Dallemand, F.Monforti,V.Motola, (2018). A spatial analysis of biogas potential from manure in Europe, Renewable and
Sustainable Energy Reviews, 94, 915930.

[14] A.O.Avcioğlu, U.Turker, (2012). Status and potential of biogas energy from animal wastes in Turkey, Renewable and Sustainable Energy Reviews, 16, 3, 1557- 1561.

[15] M.Öztürk, N.Saba, V.Altay, R.lqbal, K.R.Hakeem, M.Jawaid, F.H.Ibrahim. (2017). Biomass and bioenergy: An overview of the development potential in Turkey and Malaysia, Renewable and Sustainable Energy Reviews, 79, 1285-1302.

[16] M.Ozcan, S.Oztürk, Y.Oguz, (2015). Potential evaluation of biomass-based energy sources for Turkey, Engineering Science and Technology an International Journal, 18, 2, 178-184.

[17] F.Cucchiella, I.D’Adamo, M. Gastaldi, (2019). An economic analysis of biogas-biomethane chain from animal residues in Italy", Journal of Cleaner Production, 888-897.

[18] K.H. Klavon, S.A. Lansing, W.Mulbry, A.R. Moss, G. Felton, (2013). Economic analysis of small-scale agricultural digesters in the United States, Biomass and Bioenergy, 54, 3645 .

[19] L.A Cruz,L.de Melo, A.N.Leite,J.V. Melquiades Sátiro, L.R.Santos Andrade,N.H.Torres, R.Y.Cabrera Padilla, R.N.Bharagava, R.F.Tavares, 1.F.Romanholo Ferreira, (2019). New Approach Using An Open-Source Low Cost System For Monitoring And Controlling Biogas Production From Dairy Wastewater, Journal of Cleaner Production, 241, 118284.

[20] M.F.Baran, F.Lüle, O.Gökdoğan, (2017). Adıyaman İlinin Hayvansal Atıklardan Elde Edilebilecek Enerji Potansiyeli, Türk Tarım ve Doğa Bilimleri Dergisi, 4, 3, 245-249.

[21] A.P.Bulut, G.T.Canbaz, (2019). Hayvan Atıklarından Sivas İli Biyogaz Potansiyelinin Araştırılması, Karaelmas Fen ve Müh. Dergisi, 9, 1, 110. 
[22] D. Kaya, H.H. Öztürk, (2012). Biyogaz Teknolojisi, Umuttepe Yayınları, ISBN :978-605-59-74-7.

[23] F. Holzleitner, C. Kanzian, K. Stampfer, (2011). Analyzing time and fuel consumption in road transport of round wood with an onboard fleet manager, Eur J Forest Res, 130, 293-301.

[24] M. O. Ofomola, G. E. Akpojotor, (2009). Database of $\mathrm{CO}_{2}$ Emission In Nigeria: A Preliminary Report, Proceedings of the Second International Seminar on Theoretical Physics \& National Development, 5-8 July, 2009, Abuja, Nigeria, 267-279.

[25] https://www.enerjiatlasi.com/haber/ele ktrik-uretiminde-karbon-salinimi

[26] M.S. Genç, (2010). Economic analysis of large-scale wind energy conversion Systems in anatolian Turkey, Clean Energy Systems and Experiences ISBN: 978-953-307-147-3. 